\title{
Women's choices in Non-Invasive Prenatal Testing for aneuploidy screening: results from a single centre prior to introduction in England
}

Short running title: Women's Choices in NIPT

Manuscript word count: 2582

Manuscript table count: 4

Manuscript figure count: 2

Adalina Sacco ${ }^{1,2^{*}}$, Hilary Hewitt ${ }^{2}$, Pranav Pandya ${ }^{1,2}$

${ }^{1}$ Institute for Women's Health, University College London, London, UK

2 Fetal Medicine Department, University College London Hospital, London, UK

*a.sacco@ucl.ac.uk

07817991608

Fetal Medicine Unit, Elizabeth Garrett Anderson Wing, University College London Hospital, 235

Euston Road, London, NW1 2BU

Disclosure of Interests

PP is Chair of the Fetal Anomaly Screening Programme Advisory Group at the National Screening Committee. AS and $\mathrm{HH}$ have no disclosures of interest to declare.

Funding

This study is unfunded.

Contribution to Authorship:

PP conceived and designed the study. $\mathrm{HH}$ collected the data. AS analysed the data and drafted the manuscript. All authors contributed to further editing of the manuscript and accept responsibility for the study as submitted.

Ethical Approval:

None required. 


\section{Abstract}

\section{Objective}

To evaluate patient choices and uptake of Non-Invasive Prenatal Testing (NIPT) for aneuploidy screening offered in a contingency model as part of routine care.

\section{Method}

We retrospectively reviewed data for all women with a singleton pregnancy attending for routine first trimester screening over an 18-month period. Women with a "highchance" of trisomy 21,18 or $13(\geq 1: 150)$ were offered the choice of no further testing, NIPT or invasive testing, in line with the screening pathway recommended by the UK National Screening Committee.

\section{Results}

Of 9342 women attending for a first trimester ultrasound scan, 7939 women were included in this study. Of these, 352 had a high-chance screening result for trisomy 21, and $291(82.7 \%)$ opted for NIPT. The proportion of women opting for NIPT decreased as the chance of trisomy 21 increased: uptake was $93.2 \%, 90.0 \%, 77.1 \%$ and $47.2 \%$ for women with a chance of $1: 100-150,1: 50-99,1: 10-49$ and $>1: 10$ respectively. 516 women (5.5\%) accessed primary NIPT screening in the private sector, and 638 women (6.8\%) declined any aneuploidy screening or testing.

\section{Conclusion}

Implementation of NIPT testing in a contingency model has a high uptake in a nonresearch NHS setting; the rate of uptake is related to the combined test risk result. 
Keywords

NIPT implementation, NHS, aneuploidy, Down's syndrome, screening 
$\underline{\text { Introduction }}$

Antenatal screening for common aneuploidies - trisomies 21, 18 and 13 - has advanced rapidly over the last 30 years $^{1} 2$ from maternal age alone, through the introduction of biochemistry and nuchal translucency to the amalgamation of all of these factors in the combined test. In one meta-analysis, cell-free DNA testing (noninvasive prenatal testing, NIPT) has been shown to have a $99.7 \%$ detection rate for trisomy 21 with a false positive rate of $0.04 \% \%^{3}$. In another meta-analysis, the trisomy 21 detection rate was found to be $95.9 \%$ in a general obstetric population and $97 \%$ in a high-risk population ${ }^{4}$. These rates compare favourably to the combined screening detection rate of $85-90 \%$ and false positive rate of $3-5 \%$. NIPT has been adopted variably throughout the world ${ }^{5}$, and in many countries is only available through the private sector. There are two main models of implementation: highchance/contingency screening ${ }^{6} 7$, i.e. offering NIPT as an add-on test in high and/or intermediate risk women following their results from standard screening and lowchance/population screening (primary screening) 891011 12, i.e. offering NIPT to all women, in place of standard screening. In the UK, the National Screening Committee recommendation ${ }^{13}$ is that women who are high-chance (defined as equal to or greater than 1 in 150 from the combined test at $11+2$ to $14+1$ weeks' gestation or quadruple test from $14+2$ to $20+0$ weeks' gestation) should be offered NIPT as an additional step in the screening pathway along with the options of invasive testing or no further testing. This should come into effect in the public sector in 2019. NIPT implementation within the NHS has previously been evaluated in two studies using cut-offs of 1 in $1000^{7}$ and 1 in $2500^{6}$ for offering NIPT. Our institution implemented NIPT screening as recommended by the National Screening Committee as routine care in 2017 . This was 
funded by our Women's Health department, and partly compensated for by a decrease in invasive testing. The aim of this study was to present our results from 18 months of contingency NIPT screening as recommended by the National Screening Committee prior to national implementation. 
Methods

We retrospectively reviewed data for all women with a singleton pregnancy attending for routine first trimester screening at $11+2$ to $14+1$ weeks' gestation over an 18-month period (January 2017-June 2018). Women who declined screening, who were found to have miscarried or who underwent primary invasive testing (e.g. due to previous history) were excluded. Women who had screening privately were noted and not offered further aneuploidy screening. All other women underwent standard combined screening using maternal age, nuchal translucency, PAPP-A and free beta hCG. All women who requested screening were offered the options of Trisomy 21,18 and 13 screening, Trisomy 21 screening only or Trisomy 18 and 13 screening only.

\section{Counselling}

Women found to be high chance for trisomy 21,18 or 13 ( $\geq 1$ in 150$)$ were offered the choice of no further testing, NIPT or invasive testing. Women who wished to have further testing were referred to the Fetal Medicine Unit where the benefits and limitations of both options were explained. Women were informed that invasive testing would provide a definitive diagnosis for trisomy 21,18 and 13 but carried a small risk of miscarriage up to 1 in 100. The non-invasive benefits of NIPT testing, as well as its limitations including the fact that it remains a screening test and the possibility of no result ,were also discussed. Women were informed that NIPT was offered as an additional option outside of current National Screening Committee recommendations, although this will be introduced shortly. Women with a high-chance result who also had structural anomalies or a raised nuchal translucency $(\geq 3.5 \mathrm{~mm})$ detected on ultrasound scan were given all options and advised that in addition to QF PCR a 
microarray would be performed because of the increased risk of a chromosomal abnormality that may not be detected by NIPT alone and that invasive testing was preferable if they wished to obtain a rapid result ; however, NIPT was also offered if they did not want this. If a woman opted for NIPT and this failed to give a result, she was given the option of invasive testing or a further redraw. All women consenting to a microarray were informed that there was a risk of up to $2 \%$ of detecting a variant of uncertain significance. In this situation the result is discussed with a clinical geneticist to plan subsequent management. Women with a PAPP-A level $<0.4 \mathrm{MoM}$ detected on combined screening were counselled about the increased risk of fetal growth restriction and other adverse pregnancy outcomes, and offered aspirin and serial growth scans.

\section{NIPT test}

UCLH works in partnership with The Doctors Laboratory (TDL) and we therefore offered NIPT testing using the Harmony test (Roche), which is the only NIPT test offered by TDL. In line with NSC recommendations we do not test for microdeletions or sex chromosome analysis. The cost of this test was covered by our department, and women did not have to pay for the option of NIPT following high-chance screening.

Information on all patients undergoing routine screening, high-chance patients, further testing and results were recorded contemporaneously in a fetal database. No ethics approval was required.

\section{$\underline{\text { Results }}$}




\section{Screening results and choices}

During the 18-month study period, 9342 women were seen for a first trimester ultrasound scan at $11+2$ to $14+1$ weeks of gestation and 7939 of these women were included in this study. Figure 1 gives details of the 1403 women excluded; 638 women declined aneuploidy screening (6.8\%) and 516 women had already obtained NIPT screening privately (5.5\%); of these one woman had a high-chance result and opted for invasive testing. All women accepting screening wished to be screened for Trisomy 21,18 and 13. Overall, high chance screening results ( $\geq 1$ in 150 for trisomy 21,13 or 18) were given to 371 women screened (4.7\%). Demographic details for these women are given in Table 1.

There were 352 women with a high-chance screening result for trisomy 21 in this study (321 high chance for trisomy 21 alone and 31 also high chance for trisomies 13 or 18), representing a screen positive rate of $4.4 \%$. Of these, 116 women had a chance of 1:100-150, 90 women had a chance of 1:50-99, 109 women had a chance of 1:10-49 and 37 had a chance of $<1: 10$. In total, 291 women (82.7\%) opted for NIPT, 52 women (14.8\%) opted for invasive testing, five women (1.4\%) opted for no further testing, three women with ultrasound anomalies opted for termination of pregnancy without further testing (0.9\%) and one woman experienced a miscarriage (0.3\%) (Table 2). Of the 291 women who opted for NIPT, 271 (93.1\%) received a low-chance result, 13 $(4.5 \%)$ received a high-chance result, of whom ten proceeded to invasive testing (all positive for trisomy 21 ) and seven women (2.1\%) did not receive a result. As Figure 2 shows, the proportion of women opting for NIPT decreased as the chance of trisomy 21 increased: NIPT uptake was $93.2 \%, 90.0 \%, 77.1 \%$ and $47.2 \%$ for women with a 
chance of 1:100-150, 1:50-99, 1:10-49 and $<1: 10$ respectively. For women opting for invasive testing, aneuploidy was confirmed in $80 \%$ of women with a chance of $1: 100$ $150(4 / 5)$, no women with a chance of $1: 50-99(0 / 2), 48 \%$ of women with a chance of $1: 10-49(11 / 23)$ and $75 \%$ of women with a chance $<1: 10(15 / 20)$.

There were 19 high-chance results for trisomy 13 or 18 which were low chance for trisomy 21 , as shown in Table 3. Of these, four fetuses $(21.1 \%)$ had a significant fetal anomaly and three of the four women opted for invasive testing, with all three receiving a positive result (two trisomy 18 and one trisomy 13). One woman with a fetal cardiac anomaly and early growth restriction opted to end the pregnancy without any further testing. The remaining 15 women (78.9\%) did not have any significant fetal anomaly seen on ultrasound scan; of these, $13(92.9 \%)$ chose NIPT, all of which were negative. Two women without fetal anomalies opted for CVS. One of these women had experienced a previous pregnancy with body stalk anomaly, and her CVS result was negative; in the other the left ventricular outflow tract had not been visualised and she opted for CVS, which was positive for trisomy 18.

Overall, NIPT was chosen by 304 of the 371 women given any high- chance result (81.9\%). There were seven failures to obtain a result from a single sample $(2.3 \%)$ as shown in Table 4. Two of these women declined any further testing and five opted to repeat the sample. Of these five women, one obtained a result with repeat testing which was positive for trisomy 21 and proceeded to invasive testing, which was positive. The remaining four women experienced a second test failure; two proceeded to invasive testing, both of which were negative, one declined further testing and one opted to repeat NIPT a third time; this again failed and invasive testing was declined. 
Of the seven original test failures, one was ultimately positive for trisomy 21 , five were negative (negative CVS or examination of the neonate) and one was lost to follow up.

\section{Confirmed aneuploidies}

From 371 women with high-chance combined screening results, there were 43 chromosomal anomalies confirmed by invasive testing as follows:

- Trisomy 21: 26 pregnancies (overall rate $0.3 \%$ of all women screened or 3 in 1000).

- Trisomy 18: 8 pregnancies (overall rate $0.1 \% 1$ in 1000).

- Trisomy 13: 3 pregnancies (overall rate $0.04 \%$ or 1 in 2500 ).

- Turner's syndrome: 4 pregnancies (three full $45 X$, one mosaic)

- 22q deletion: one pregnancy

Termination of pregnancy was chosen by 52 women, including four who chose this following a high-chance combined screening result (two for trisomies 21, 18 and 13, one for trisomy 21 and one for trisomy 18/13) without any further testing. In all of these four cases there were additional abnormalities detected on ultrasound at the time of combined screening. 


\section{Discussion}

\section{Main Findings}

In this study, over eighty percent of women with a high-chance combined screening result opted for NIPT testing first-line, with the vast majority $(91.6 \%)$ receiving a lowchance result following this. The uptake of NIPT which we found correlates with the RAPID study ${ }^{7}$, also performed in a UK setting, which found that $74.4 \%$ of women with a trisomy 21 chance greater than 1 in 150 chose NIPT. However, a study from Kings College London ${ }^{6}$ found that only $60.0 \%$ of women with a trisomy 21 chance greater than 1 in 100 opted for NIPT, whereas we found a much higher uptake. In this study, $37.6 \%$ of high-chance women opted for invasive testing rather than NIPT, which is higher than we have found in our practices. Similarly, a prospective trial in Hong Kong ${ }^{14}$ found that $62.2 \%$ of high-chance ( $\geq 1: 250$ ) women opted for NIPT, with $36.9 \%$ choosing invasive testing. These differences may be due to differences in local demographics, counselling provided (in our institution all women opting for NIPT are seen in the FMU for a detailed discussion) or in patient education and advertisement.

The RAPID study ${ }^{7}$ compared patient decisions regarding NIPT in a contingency model to national data regarding patient decisions prior to the availability of NIPT. This national data showed that in 2011 to 2012,698500 pregnancies were screened with 10635 women receiving a high-chance combined screening result for trisomy 21 . Of these $5743(54.0 \%)$ had an invasive test, leading to 29 presumed procedure-related miscarriages $(0.5 \%$ of all invasive procedures). In this study we have found that, when NIPT is also offered following high-chance combined screening, the rate of invasive testing is $18.6 \%$ (either directly following the initial high-chance combined screening 
result, or following high-chance or no-result NIPT). Applying this theoretically to the national data used in RAPID, the number of invasive procedures following highchance screening for 10635 women would reduce from 5743 to 1978 and the number of procedure-related miscarriages would reduce from 29 to ten. However, if the rate of procedure-related miscarriages has been overestimated in the RAPID study, then the reduction in these with NIPT may also be overestimated.

During the time period assessed, we were made aware that 516 women from the full cohort of 9342 attending for first trimester scans (5.5\%) had already accessed NIPT, themselves in the private sector, and others may have done so without our knowledge. This suggests an appetite for wider implementation of NIPT screening to include lowchance women and be offered as a first-line choice. This model of screening has recently been introduced in Holland and Belgium. It is also worth noting that 638 women $(6.8 \%)$ from the full cohort declined any screening, which correlates with previous work regarding uptake of prenatal screening ${ }^{15}$. In addition, following a highchance combined test five women (1.3\%) declined any further testing, which is much lower than the corresponding group prior to the offer of NIPT, when $40 \%$ of women with a high chance result declined any further testing ${ }^{7}$.

This study found a primary test "failure" of $2.3 \%$, which is in keeping with previous published rates ${ }^{3}{ }^{16}$. The management of such cases is challenging, and we found that four out of seven patients $(57.1 \%)$ opted to repeat the test, with three quarters $(3 / 4)$ of these tests again failing. 
Women with a high-chance result for trisomy 18 and/or 13 only have not been as well studied as women with a high-chance result for trisomy 21 . In our unit such women are offered a detailed fetal medicine scan in the first instance; all options (no further testing, NIPT and invasive testing) are then discussed. In the presence of additional anomalies, women are informed that invasive testing will give more information and avoid delays as a positive NIPT result should still be confirmed with invasive testing, and a negative NIPT result in a case of fetal anomalies does not give information on any other possible genetic cause. If invasive testing is chosen then a CVS is performed. If NIPT is chosen and is high-chance, an amniocentesis is offered from 15 weeks due to the increased risk of an inconclusive result with CVS in this situation ${ }^{17}$. If the NIPT is low chance a detailed scan is performed at 20 weeks. Our results show that, using this model, we avoid NIPT and can minimise the delay in making a diagnosis in the presence of fetal anomalies. In the absence of fetal anomalies NIPT provides reassurance and reduces the number of invasive procedures.

\section{Interpretation}

The introduction of NIPT as an additional step in our routine aneuploidy screening at UCLH is appears to be desirable to women. However, whilst patient acceptability could be inferred from uptake, further qualitative data regarding patient opinions would also be welcomed. It has been shown that a number of women accepting NIPT are not considered to be making an informed choice ${ }^{18}$, and following the Montgomery vs NHS Lanarkshire case in $2015^{19}$ there is an increased emphasis on care-providers to ensure that all possible risks of action - or inaction - as they are currently known are discussed and explained thoroughly. Maintaining high levels of information and 
consistent, personalised counselling whilst implementing NIPT nationally within the NHS will be an important challenge ${ }^{20}$.

\section{$\underline{\text { Conclusion }}$}

Implementation of NIPT testing in a contingency model appears desirable to patients, with higher uptake in this non-research NHS setting than might be expected from previous studies. The main challenges are cost, informed consent and management of 'no result'. In addition we need to further explore patient opinions and consider the maintenance of laboratory quality standards with increasing sample volumes. 
What's already known about this topic?

- Non-invasive prenatal testing (NIPT) for trisomy 21, 18 and 13 has been investigated in range of implementation models

- The UK National Screening Committee has recommended offering NIPT to women with a combined screening chance of $\geq 1: 150$

- Previous studies applying this cut-off in the UK shows a patient NIPT uptake of $60-75 \%$

What does this study add?

- NIPT uptake following a high-chance combined screening result $\geq 1: 150$ was $83 \%$, with the proportion decreasing as the chance of trisomy 21 increased

- NIPT appears desirable to women in a non-research, NHS setting

- Our results may provide some guidance on expected numbers for units beginning to implement NSC recommendations 


\section{$\underline{\text { References }}$}

1. Driscoll DA, Gross S. Prenatal Screening for Aneuploidy. N Engl J Med. 2009;360(24):25562562. doi:10.1056/NEJMcp0900134.

2. Nicolaides K. Screening for fetal aneuploidies at 11 to 13 weeks. Prenat Diagn. 2011;31:7-15.

3. Gil MM, Accurti V, Santacruz B, Plana MN, Nicolaides KH. Analysis of cell-free DNA in maternal blood in screening for aneuploidies: updated meta-analysis. Ultrasound Obstet Gynecol. 2017;50(3):302-314. doi:10.1002/uog.17484.

4. Taylor-phillips S, Freeman K, Geppert J, et al. Accuracy of non-invasive prenatal testing using cell-free DNA for detection of Down, Edwards and Patau syndromes : a systematic review and meta-analysis. BMJ Open. 2016;6(e010002). doi:10.1136/bmjopen-2015-010002.

5. Minear MA, Lewis C, Pradhan S, Chandrasekharan S. Global perspectives on clinical adoption of NIPT. Prenat Diagn. 2015;35(10):959-967. doi:10.1002/pd.4637.

6. Gil MM, Revello R, Poon LC, Akolekar R, Nicolaides KH. Clinical implementation of routine screening for fetal trisomies in the UK NHS: Cell-free DNA test contingent on results from firsttrimester combined test. Ultrasound Obstet Gynecol. 2016;47(1):45-52. doi:10.1002/uog.15783.

7. Chitty LS, Wright D, Hill M, et al. Uptake, outcomes, and costs of implementing non-invasive prenatal testing for down syndrome into NHS maternity care: Prospective cohort study in eight diverse maternity units. Obstet Gynecol Surv. 2016;71(11):637-639. doi:10.1097/OGX.0000000000000385.

8. Nicolaides KH, Syngelaki A, Ashoor G, Birdir C, Touzet G. Noninvasive prenatal testing for fetal trisomies in a routinely screened first-trimester population. Obstet Gynecol Surv. 2013;68(3):173-175. doi:10.1097/OGX.0b013e318285bf66.

9. Dan S, Wang W, Ren J, et al. Clinical application of massively parallel sequencing-based prenatal noninvasive fetal trisomy test for trisomies 21 and 18 in 11105 pregnancies with mixed risk factors. Prenat Diagn. 2012;32(13):1225-1232. doi:10.1002/pd.4002.

10. Bianchi DW, Lamar Parker R, Wentworth J, et al. DNA sequencing versus standard prenatal aneuploidy screening. Obstet Gynecol Surv. 2014;69(6):319-321. doi:10.1097/01.ogx.0000451481.18231.1b.

11. Norton ME, Jacobsson B, Swamy GK, et al. Cell-Free DNA Analysis for Noninvasive 
Examination of Trisomy. Obstet Gynecol Surv. 2015;70(8):483-484.

doi:10.1097/01.ogx.0000470657.58577.f2.

12. Zhang $\mathrm{H}$, Gao $\mathrm{Y}$, Jiang $\mathrm{F}$, et al. Non-invasive prenatal testing for trisomies 21,18 and 13 :

Clinical experience from 146958 pregnancies. Ultrasound Obstet Gynecol. 2015;45(5):530538. doi:10.1002/uog.14792.

13. UK National Screening Committee Non-Invasive Prenatal Testing (NIPT) recommendation. http://legacy.screening.nhs.uk/fetalanomalies.

14. Cheng YKY, Leung WC, Leung TY, et al. Women's preference for non-invasive prenatal DNA testing versus chromosomal microarray after screening for Down syndrome : a prospective study. BJOG An Int J Obstet Gynaecol. 2018;125:451-459. doi:10.1111/1471-0528.15022.

15. Rowe R, Puddicombe D, Hockley C, Redshaw M. Offer and uptake of prenatal screening for Down syndrome in women from different social and ethnic backgrounds. Prenat Diagn. 2008;28:1245-1250.

16. Revello R, Sarno L, Ispas A, Akolekar R, Nicolaides KH. Screening for trisomies by cell-free DNA testing of maternal blood: Consequences of a failed result. Ultrasound Obstet Gynecol. 2016;47(6):698-704. doi:10.1002/uog.15851

17. Grati FR, Bajaj K, Malvestiti F, et al. The type of feto-placental aneuploidy detected by cfDNA testing may influence the choice of confirmatory diagnostic procedure. Prenat Diagn. 2015;35(10):994-998. doi:10.1002/pd.4659.

18. Lewis C, Hill M, Chitty LS. Offering non-invasive prenatal testing as part of routine clinical service. Can high levels of informed choice be maintained? Prenat Diagn. 2017;37(11):11301137. doi:10.1002/pd.5154.

19. Chan SW, Tulloch E, Cooper ES, Smith A, Wojcik W, Norman JE. Montgomery and informed consent: Where are we now? BMJ. 2017;357(May):10-12. doi:10.1136/bmj.j2224.

20. Lewis C, Hill M, Chitty LS. A qualitative study looking at informed choice in the context of noninvasive prenatal testing for aneuploidy. Prenat Diagn. 2016;36:875-881. doi:10.1002/pd.4879. 


\begin{tabular}{|c|c|c|c|c|c|}
\hline \multicolumn{2}{|c|}{ Demographic details } & \multirow{2}{*}{$\begin{array}{c}\begin{array}{c}\text { All women } \\
\text { screened } \\
n=7939\end{array} \\
33.9\end{array}$} & \multirow{2}{*}{$\begin{array}{l}\text { Women with } \\
\text { any high- } \\
\text { chance result } \\
n=371 \\
37.0\end{array}$} & \multirow{2}{*}{$\begin{array}{c}\begin{array}{c}\text { Women } \\
\text { opting for } \\
\text { NIPT } \\
\mathbf{n}=\mathbf{3 0 4}\end{array} \\
37.2\end{array}$} & \multirow{2}{*}{ 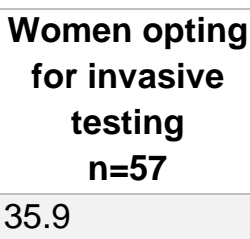 } \\
\hline Age (years) & Average & & & & \\
\hline & Range & $17-53$ & $19-49$ & $22-49$ & $21-45$ \\
\hline \multirow[t]{2}{*}{ Weight (kg) } & Average & 65.4 & 67.3 & 67.1 & 63.9 \\
\hline & Range & $37-164$ & $42-130$ & $42-130$ & $44-107$ \\
\hline \multirow[t]{5}{*}{ Ethnicity n (\%) } & White & $5748(72.4)$ & $241(65.0)$ & $197(64.8)$ & $38(66.7)$ \\
\hline & Black & $796(10.0)$ & $40(10.8)$ & $35(11.5)$ & $2(3.5)$ \\
\hline & South Asian & $695(8.8)$ & $34(9.2)$ & $26(8.6)$ & $7(12.3)$ \\
\hline & East Asian & $461(5.8)$ & $41(11.1)$ & $35(11.5)$ & $6(10.5)$ \\
\hline & Mixed & $239(3.0)$ & $15(4.0)$ & $11(3.6)$ & $4(7.0)$ \\
\hline $\begin{array}{l}\text { Assisted conception } \\
\mathrm{n}(\%)\end{array}$ & & $594(7.5)$ & $48(12.9)$ & $43(14.1)$ & $5(8.8)$ \\
\hline
\end{tabular}

Table 1: Demographic details of women screened 


\begin{tabular}{|c|c|c|}
\hline \multicolumn{3}{|c|}{$\begin{array}{l}\text { High-Chance Trisomy } 21 \text { Result } \\
\qquad n=352\end{array}$} \\
\hline Option / Result & Details & $\begin{array}{c}\text { Number of women } \\
\text { (\%) }\end{array}$ \\
\hline \multicolumn{2}{|l|}{ Invasive testing } & $52(14.8)$ \\
\hline No aneuploidy detected & & $23(44.2)$ \\
\hline Trisomy 21 & - Post-procedure miscarriage & $\begin{array}{l}16(30.8) \\
-\quad 1(1.9)\end{array}$ \\
\hline Trisomy 18 & & $5(9.6)$ \\
\hline Turners syndrome & Three full Turners, one mosaic & $4(7.7)$ \\
\hline Trisomy 13 & & $2(3.8)$ \\
\hline 22q deletion & & $1(1.9)$ \\
\hline FADS & Fetal Akinesia Deformation Sequence & $1(1.9)$ \\
\hline \multicolumn{2}{|l|}{ NIPT } & $291(82.7)$ \\
\hline Low chance & & $271(93.1)$ \\
\hline High chance & $\begin{array}{l}\text { Invasive testing } \\
\quad-\quad \text { Trisomy } 21 \\
\text { Declined further testing } \\
\text { Miscarriage }\end{array}$ & $\begin{array}{l}13(4.5) \\
10 \\
-10 \\
2 \\
1\end{array}$ \\
\hline Failure to obtain result & $\begin{array}{l}\text { Repeat attempt } \\
-\quad \text { Second failure } \\
-\quad \text { High chance result (declined further } \\
\text { testing) } \\
\text { Declined further testing }\end{array}$ & $\begin{array}{l}7(2.1) \\
4 \\
-3 \\
-1 \\
3\end{array}$ \\
\hline \multicolumn{2}{|l|}{ No further testing } & $5(1.4)$ \\
\hline \multicolumn{2}{|c|}{ Termination of pregnancy (without further testing) } & $3(0.9)$ \\
\hline \multicolumn{2}{|l|}{ Miscarriage } & $1(0.3)$ \\
\hline
\end{tabular}

Table 2: Options chosen by women with high-chance screening results for trisomy $21 \geq 1: 150$. 


\begin{tabular}{|c|c|c|c|c|c|c|}
\hline $\begin{array}{c}T 13 / 18 \\
\text { chance } \\
(1: n)\end{array}$ & $\begin{array}{c}\text { Nuchal } \\
\text { Translucency } \\
(\mathrm{mm})\end{array}$ & $\begin{array}{l}\text { hCG } \\
\text { MOM }\end{array}$ & $\begin{array}{c}\text { PAPP-A } \\
\text { MOM }\end{array}$ & $\begin{array}{c}\text { Gestational } \\
\text { Age } \\
\text { (weeks + days) }\end{array}$ & $\begin{array}{l}\text { Additional } \\
\text { anomalies }\end{array}$ & $\begin{array}{l}\text { Maternal } \\
\text { choice and } \\
\text { results }\end{array}$ \\
\hline 8 & 8.5 & 0.1285 & 0.1811 & $12+4$ & $\begin{array}{l}\text { Megacystis, possible cardiac } \\
\text { anomaly, clenched hands, SUA }\end{array}$ & CVS - T18 - TOP \\
\hline 19 & 2.3 & 0.1300 & 0.1461 & $13+2$ & $\begin{array}{l}\text { Exomphalos, aortic anomaly } \\
\text { strawberry-shaped head, SUA }\end{array}$ & CVS - T18 - TOP \\
\hline 31 & 1.3 & 0.4121 & 0.0603 & $12+4$ & SUA & NIPT - low chance \\
\hline 58 & 1.3 & 0.3771 & 0.0520 & $12+5$ & Early IUGR, cardiac anomalies & TOP \\
\hline 60 & 1.5 & 0.4301 & 0.1550 & $13+4$ & Nil & NIPT - low chance \\
\hline 72 & 1.1 & 0.3471 & 0.2083 & $12+2$ & Nil & NIPT - low chance \\
\hline 79 & 1.6 & 0.4685 & 0.1772 & $12+1$ & Nil & CVS - negative \\
\hline 80 & 1.5 & 0.4203 & 0.1607 & $12+4$ & Nil & NIPT - low chance \\
\hline 83 & 1.6 & 0.1008 & 0.2629 & $12+2$ & $\begin{array}{l}\text { Unable to view left ventricular } \\
\text { outflow tract; nil else }\end{array}$ & CVS - T18 - TOP \\
\hline 84 & 2.1 & 0.6505 & 0.3145 & $12+6$ & Nil & NIPT - low chance \\
\hline 92 & 2.4 & 0.1368 & 0.3114 & $14+0$ & Nil & NIPT - low chance \\
\hline 93 & 2.0 & 0.2607 & 0.1872 & $12+3$ & Nil & NIPT - low chance \\
\hline 96 & 1.2 & 0.4028 & 0.2757 & $12+1$ & Nil & NIPT - low chance \\
\hline 96 & 1.9 & 0.3716 & 0.2825 & $12+1$ & $\begin{array}{l}\text { Facial cleft, cardiac, enlarged } 4^{\text {th }} \\
\text { ventricle }\end{array}$ & CVS - T13 - TOP \\
\hline 106 & 1.9 & 0.2768 & 0.2996 & $13+3$ & Nil & NIPT - low chance \\
\hline 133 & 1.4 & 1.0802 & 0.3022 & $12+2$ & Nil & NIPT - low chance \\
\hline 143 & 2.1 & 0.6872 & 0.2202 & $13+0$ & Nil & NIPT - low chance \\
\hline 147 & 2.0 & 0.4140 & 0.2413 & $13+3$ & Nil & NIPT - low chance \\
\hline 149 & 2.2 & 0.3658 & 0.2681 & $12+2$ & Nil & NIPT - low chance \\
\hline
\end{tabular}

Table 3: Details of women with high-chance results for Trisomy 13 and/or 18.

T13: Trisomy 13, T18: Trisomy 18, T 21: Trisomy 21, CRL: crown-rump length, CVS: chorionic villus sampling, hCG: human chorionic gonadotropin, PAPP-A: pregnancy associated plasma protein-A, SUA: single umbilical artery, TOP: termination of pregnancy 


\begin{tabular}{|c|c|c|c|c|}
\hline $\begin{array}{c}\text { T21 } \\
\text { chance } \\
(1: n)\end{array}$ & $\begin{array}{c}\text { Gestational } \\
\text { age } \\
\text { (weeks + days) }\end{array}$ & $\begin{array}{c}\text { Maternal } \\
\text { weight } \\
(\mathrm{kg})\end{array}$ & Ethnicity & Decision and Outcome \\
\hline 15 & $11+6$ & 57.9 & White & NIPT repeated - second failure. CVS performed - negative \\
\hline 40 & $12+2$ & 90.4 & South Asian & Declined further testing. No signs of T21 on neonatal follow-up. \\
\hline 76 & $11+4$ & 65.5 & East Asian & NIPT repeated - second failure. CVS performed - negative \\
\hline 90 & $11+2$ & 58.0 & White & $\begin{array}{l}\text { NIPT repeated - high chance T21 result. CVS performed - } \\
\text { positive for T21. Termination of pregnancy. }\end{array}$ \\
\hline 122 & $12+4$ & 51.0 & Not stated & $\begin{array}{l}\text { NIPT repeated twice more - two further failures. Invasive testing } \\
\text { declined. No neonatal follow-up available. }\end{array}$ \\
\hline 124 & $12+4$ & 74.0 & White & $\begin{array}{l}\text { NIPT repeated - second failure. Declined invasive testing. No } \\
\text { signs of T21 on neonatal follow-up. }\end{array}$ \\
\hline 142 & $13+3$ & 83.3 & South Asian & Declined further testing. No signs of T21 on neonatal follow-up. \\
\hline
\end{tabular}

Table 4: Details of women in whom NIPT testing failed to give a result on first attempt. 